\title{
Imagem
}

\section{Aneurisma Gigante Ventricular Esquerdo}

\section{Giant Left Ventricular Aneursym}

\section{Sait Demirkol ${ }^{1}$ e Uygar Cagdas Yuksel²}

Malatya Army District Hospital'; Sarikamis Army District Hospital² - Turkey

Uma paciente do sexo feminino de 68 anos, com aneurisma gigante ventricular esquerdo causado por extenso infarto do miocárdio prévio, veio ao nosso ambulatório, queixando-se de falta de ar. O diâmetro mediolateral do aneurisma era de $72 \mathrm{~mm}$, o que é muito maior do que o ventrículo em si (Figura 1). A fração de ejeção do ventrículo esquerdo era de
35\%. A paciente tinha um histórico de uso de altas doses de anti-inflamatórios não-esteroides devido à sua artrite crônica, o que pode ter possivelmente contribuído para a expansão do seu grande aneurisma. A presença de hipertensão e o uso de esteroides e anti-inflamatórios não-esteroides podem promover a formação de aneurismas.

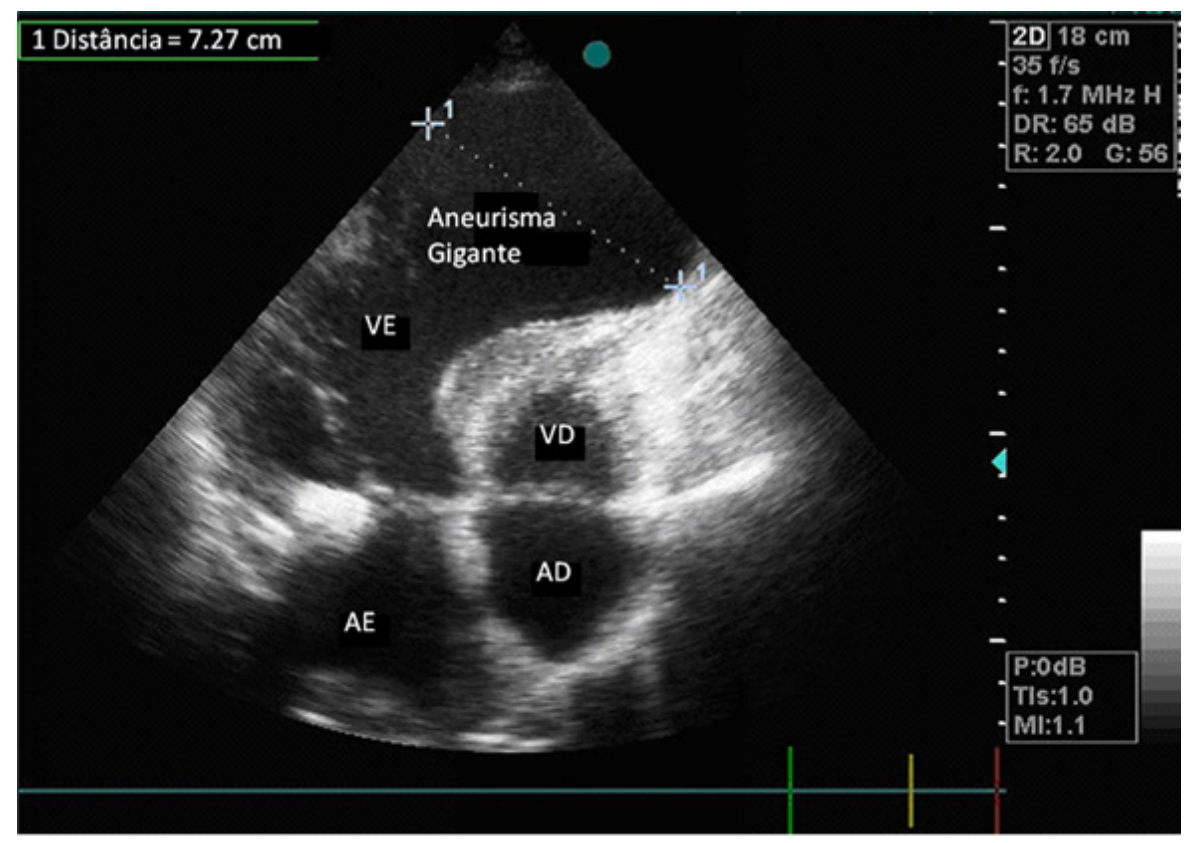

Fig. 1 - Aneurisma gigante do VE causado por um extenso infarto do miocárdio cicatrizado; $A E$ - átrio esquerdo; VE - ventrículo esquerdo; $A D$ - átrio direito; VD - ventrículo direito.

\section{Palavras-chave}

Aneurisma, infarto do miocárdio. 